\title{
Implementation of Fuzzy and PID Controller to Water Level System using LabView
}

\author{
Laith Abed Sabri, Ph.D \\ University of Baghdad \\ AL-Khwarizmi college of Engineering
}

\author{
Hussein Ahmed AL-Mshat \\ University of Baghdad \\ AL-Khwarizmi college of Engineering
}

\begin{abstract}
The paper is about the water level control system which is required in many industrial processes like water treatment plant, the idea of the process is to keep the tank water level at the desired set point. First we implemented the conventional proportional - integral - derivative (PID) controller to eliminate the steady state error, then it was used Fuzzy logic controllers which gives more performance and stability. It is noted from the results that the Fuzzy Logic controller is more enhanced than PID controller in which its no overshoot, faster settling time, better set point tracking and produced lower performances like integral of time and absolute error (ITAE) integral of time and squared error (ITSE), and integral absolute error (IAE), integral squared error (ISE).
\end{abstract}

Both PID and fuzzy controller are implemented using LabView software

\section{Keywords}

Proportional-integral-derivative (PID) controller, Fuzzy Controller, LabView

\section{INTRODUCTION}

One of the basic problems in the industries is water level controlling system. Level of liquid being an important process parameter has to be maintained at the desired level for smooth running of the process and for better quality products.All of the process industries, water treatment plants, and nuclear power plants be contingent upon controlling the level in tank systems. It is vital for engineers work in these plants especially control and mechatronics engineer to have a good understanding to how the tank level controlling system work and how the level control difficult is managed.

Most of the control performances in the actual design are usually defined by overshoots, rising time, settling time, steady state error, etc. [1,2].

Proportional-Integral-Derivative(PID)controller is the simple, reliable and accurate used in industrial feedback control loops, PID controller can't be used to control the complex system to get the better performance[3].

The engineers in the past was used the mathematical model of the system to design a controller based on a linearized model of real control systems, but the problem is that the response of complex and non-linearity of real process is hard to find by applying conventional control techniques (like PID controller) some experiments appearance that the simple PID with constant parameter not achieve response of level tank system $[4,5]$.
Using intelligent system like Fuzzy controller can consider an effective ways to solve this problem Fuzzy controller have a logical of the human behaviour in make decision. And as result gives the better performance than PID controllers in terms of settling and rising, response time, overshoot and robustness $[6,7,8]$.

In this paper, fuzzy and PID controller is designed and applied to the Water level system. Then the fuzzy controller is used to make the system fast and stable.in result a comparison between two controllers was presented.

\section{TANK MATHMATICAL MODEL}

The tank system model can write in mathematical form by relating the inlet flow of the tank $Q_{\text {in }}$ to the outlet flow $Q_{\text {out }}$ through drainage pipe using balance flows equation:

$\mathbf{Q}_{\text {in }-} \mathbf{Q}_{\text {out }}=A \frac{d H}{d t}$

Where:

A: Tank cross-sectional area

$\mathrm{H}$ : water level in the Tank.

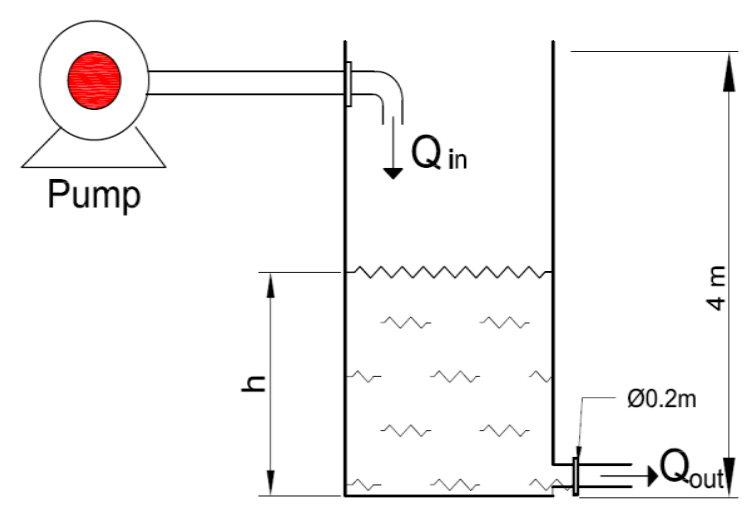

Fig 1: Single tank water level system

The level of the tank is the integration of the above equation:

$H=\int \frac{1}{A}(q i-q o u t) d t$

Beside if there is no pump sucking out the water from the drainage pipe, the outgoing flow will be:

qout $=a \times \sqrt{2 g h}$

Where a: Area of the pipe

$\sqrt{\mathbf{2 g h}}$ : The velocity of outgoing water

The SISO (single input single output) tank system is designed according to the model in eq. (2). The mathematical block diagram for the model in eq. (2) as shown in the Figure 2. 


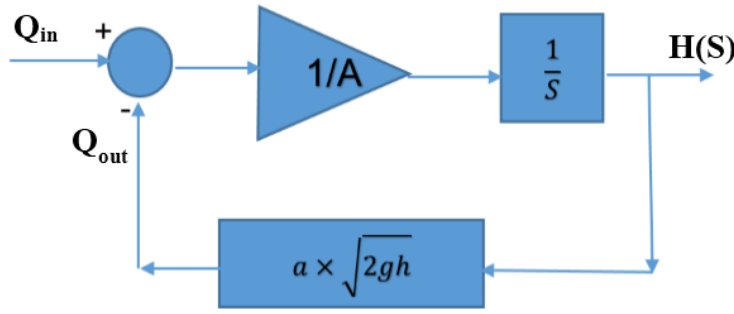

Fig 2: The block diagram of the tank level with an inlet and an outlet flow

\section{PID CONTROLLER DESIGN}

The PID controlling jobs is to adjust the output at a level so that there is no error (the difference between the sensing value (SV) and the set point (SP)).

General architectural of PID controller is shown in Figure 3, the error e(s) is the controller input and the actuator input is the controller output $\mathrm{u}(\mathrm{s})$.

e(s)

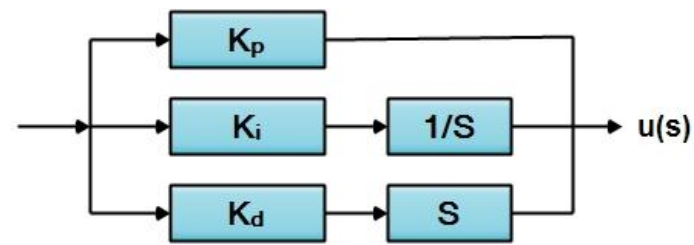

Fig 3: Block diagram of PID Controller

The PID controller governing equation is:

$m_{P I D}(t)=K_{p} e(t)+K_{p} K_{i} \int e(t) d t+K_{p} K_{d} \frac{d e(t)}{d t}$

The PID controller output in terms of Laplace transform can be written as:

$M_{P I D}(s)=K_{p}\left(1+\frac{1}{T_{i} s}+T_{d} s\right) \ldots(5)$

Figure 6 show the schematic design for our system based in LabView program, Figure 4 is the water tank system GUI (Graphical User Interface) with PID controller made by LabView ,the user can change the set point which in this case is like input value for control system, while the Figure 5 present the Block Diagram (BD) for the system in LabView

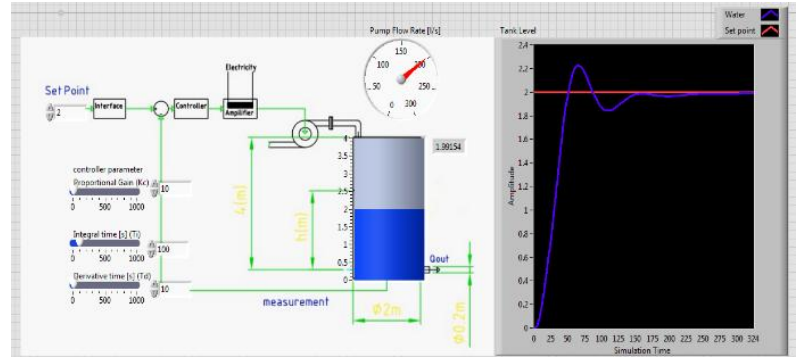

Fig 4: Front panel of tank level controlled by academic PID

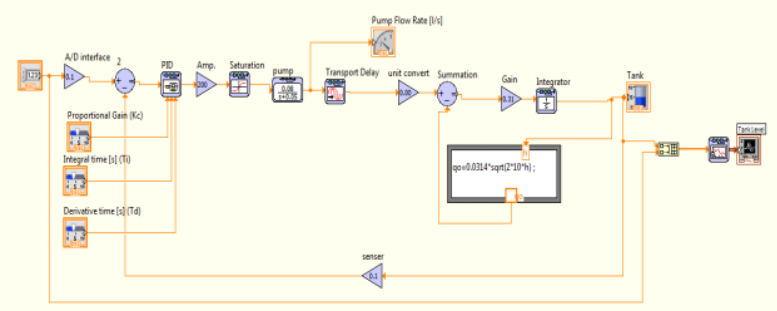

Fig 5: Block diagram in LabView program for PID controlling of the tank

The block diagram below explain the component of the PID controlling of the tank

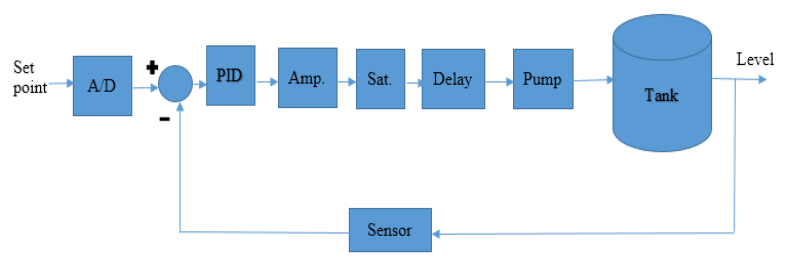

Fig 6: Schematic diagram for PID control

According to PID controller's simplicity and excellent performance, it were used in more than $95 \%$ industrial processes at many applications. The PID controller can be tuned by using off-line control methods as well as online control methods. The control techniques of complex dynamic systems with nonlinear or time varying behaviour are very difficult to determine the model of the process $[9,10]$.

\section{FUZZY CONTROLLER DESIGN}

Fuzzy controller is able to summarize human knowledge of the system and integrate them to the laws of control.Fuzzy control system design depending on (a) adjusting the fuzzy input and output memberships (b) regular the rule base table and (c) designing each of the four components of the fuzzy controller as shown in Figure 8 [11,12]. 


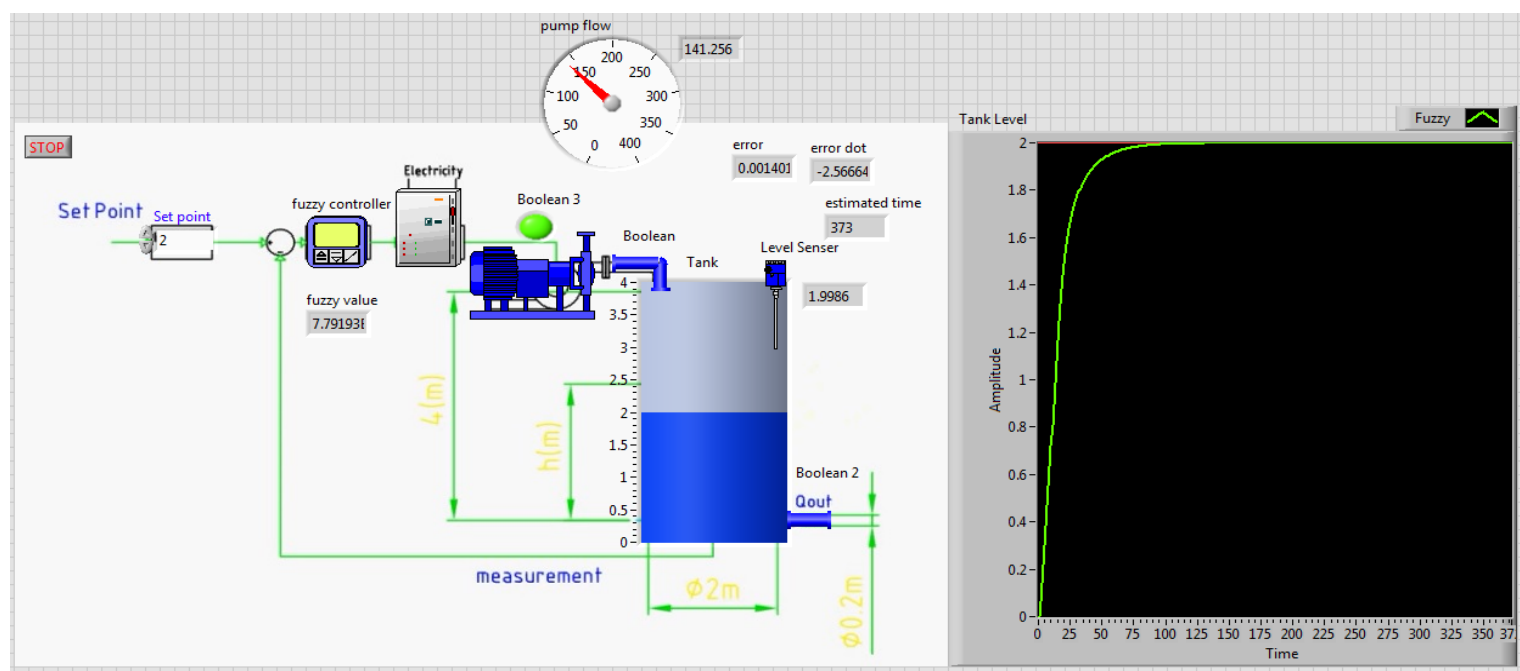

Fig 7: Front panel of tank level process with fuzzy controller

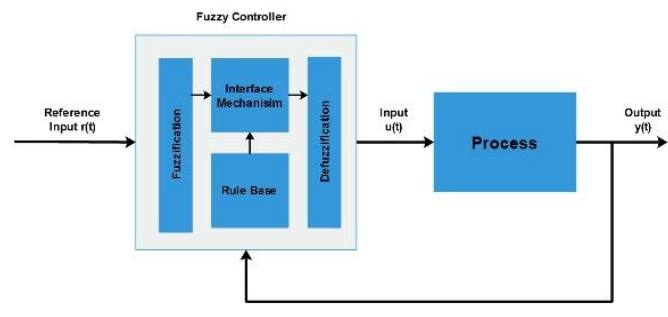

Fig 8: Fuzzy controller architecture

For our case the input variable for tank level control is error $e(t)$ and differential error $e^{*}(t)$ while The output $(y)$ is the control signal to the actuator.

\section{Inputs and Output Subsets}

Input1 (level Error): Negative High (NH), Negative (N), Small (S), Positive (P), and Positive High (HP)

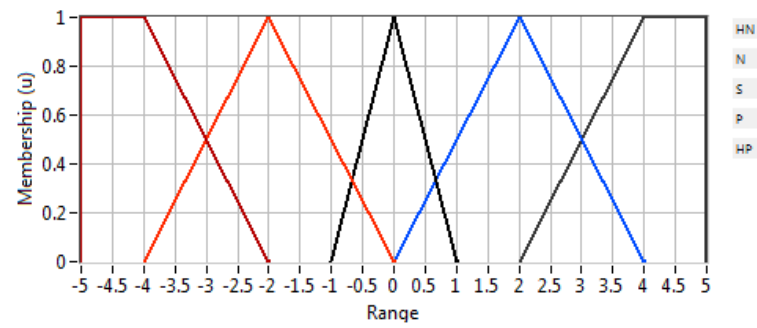

Fig 9: Membership function for error

Input 2 (Error Rate Level): Negative, Small, and Positive

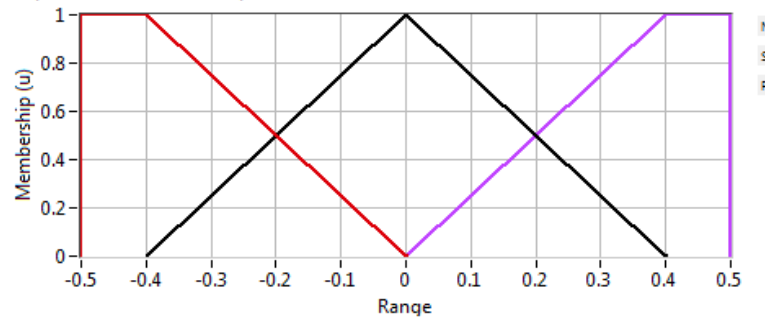

Fig 10: Membership function for error rate

Output: Negative High, Negative, Zero, Positive, and Positive High

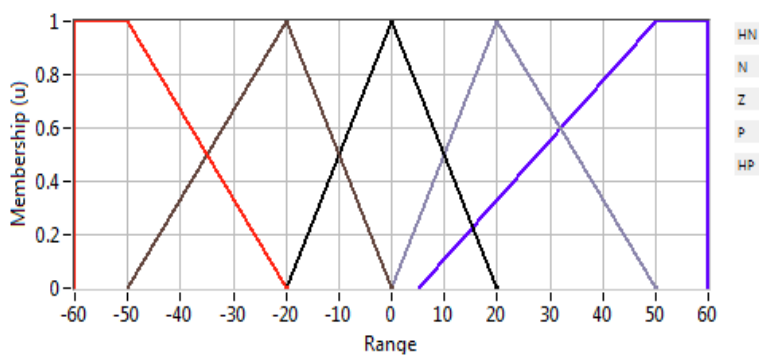

Fig 11: Membership function for output Response

The relations between the inputs to output of the system are shown by the rule base in Table 1 . Which show that for any possible value of the two inputs, there is an output based on the rules. Fuzzy rule consider an alteration between linguistic control understanding of an expert and automatic control plans of an activator [13].

Table 1. The Rule Base

\begin{tabular}{|c|c|c|c|c|c|}
\hline$e^{-}$ & HN & N & S & P & HP \\
\hline N & HN & N & P & HP & HP \\
\hline$S$ & HN & N & $Z$ & P & HP \\
\hline$P$ & HN & $Z$ & N & $Z$ & HP \\
\hline
\end{tabular}

The final step in designing fuzzy controller in LabVIEW Program is using the test system as shown in Figure11, in which the response of the system can be enhance the rule base of the fuzzy controller and adjusting the output value through changing the range of the membership for input and output values [14].

Figure 7 Show the GUI which implemented by LabView while Figure 13.Present the Block Diagram with fuzzy controller 


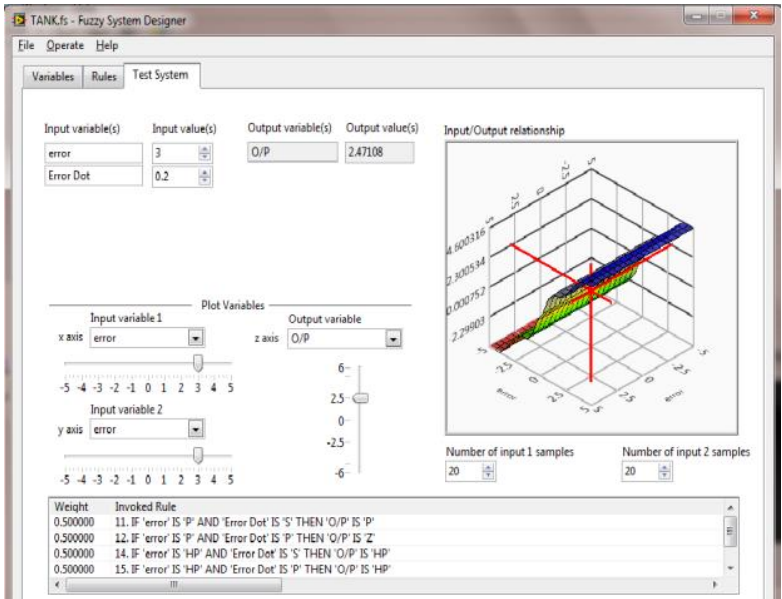

Fig 12: Input/output relationship of the system

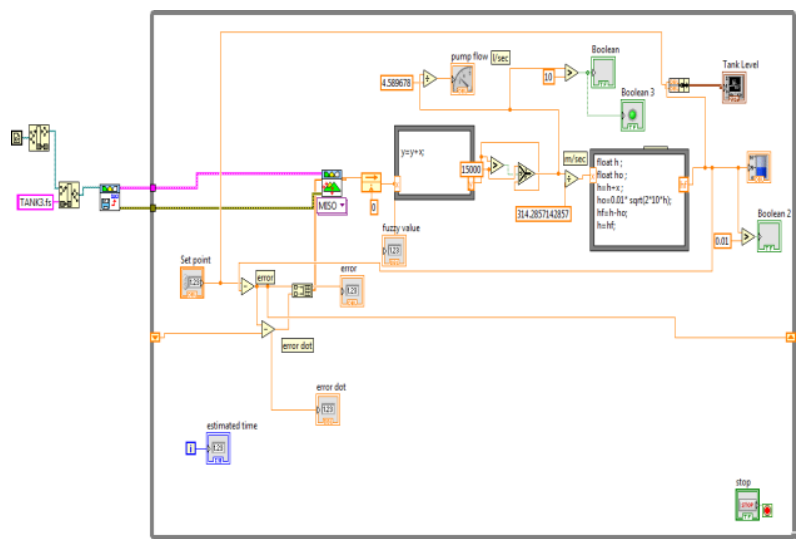

Fig 13: Block diagram of tank level adjusted with fuzzy controller

\section{RESULTS}

The PID controller is tuned, where the proportional gain $K p=$ 10, integral time $T i=100$ and derivative time $T d=10$. Fig. 8(a) represents the response of the PID controller which has settling time of $250 \mathrm{sec}$ and rise time of $34 \mathrm{sec}$. overshoot $=11.2 \%$ and The response of fuzzy controller is shown in Fig. 14 (b) with setting time $105 \mathrm{sec}$ and rise time $29 \mathrm{sec}$ we observe that there is no peak value appeared in the curve so there is no over shoot calculated.the water level controlled by Fuzzy controller faster response with the more ability to reach the stability than conventional PID controller which assistances in increase the performance of the system.

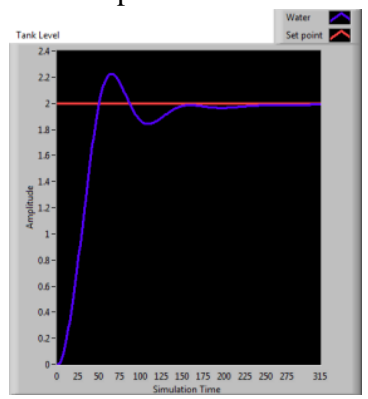

(a)

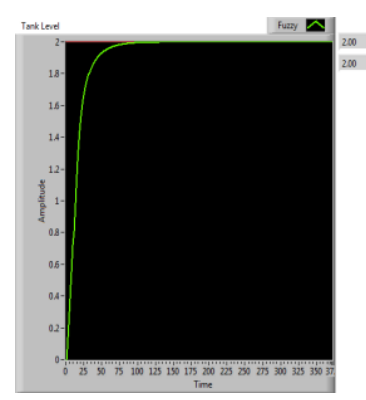

(b)

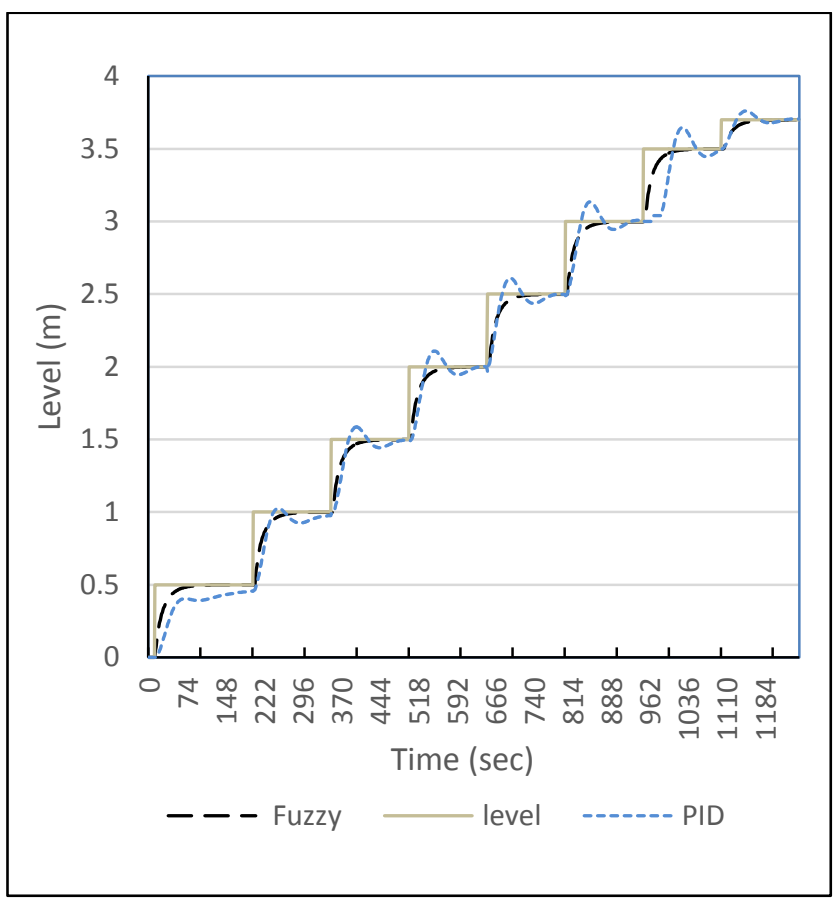

(c)

Fig (14) (a) Response of PID controller, (b)) Response of fuzzy controller(c) comparison between PID and Fuzzy controller in step response

The comparison of transient responses such as overshoot, settling time and rise time for the two controllers are shown in table 2.

Table 2 Comparison of transient response

\begin{tabular}{|l|c|c|c|}
\hline Type & Overshoot \% & $\begin{array}{c}\text { Settling } \\
\text { time (sec) }\end{array}$ & $\begin{array}{c}\text { Rise } \\
\text { time } \\
\text { (sec) }\end{array}$ \\
\hline PID & $11.2 \%$ & 250 & 34 \\
\hline Fuzzy & No Overshoot & 105 & 29 \\
\hline
\end{tabular}

From the table 2 and Fig 14, it is observed that the fuzzy controller has No overshoot like PID controller and take less time to reach the steady state.

The error indices such as (IAE), (ISE), (ITAE) and (ITSE) for PID controller and fuzzy controller are compared in table 3. 
Table (3) comparison of error indicated

\begin{tabular}{|l|l|l|l|l|}
\hline Type & IAE & ISE & ITAE & ITSE \\
\hline PID & 0.362224 & 0.509354 & 9.453114 & 4.988225 \\
\hline Fuzzy & 0.196873 & 0.235035 & 2.841599 & 1.603642 \\
\hline
\end{tabular}

From the table, the absolute error of fuzzy controller is $45.6 \%$ less than PID controller, the squared error is also $53.9 \%$ less than that of PID controller. Similarly, the ITAE and ITSE of fuzzy controller are $69.9 \%$ and $67.9 \%$ less than PID controller.

\section{CONCLUSION}

This paper presents the control of the level in a single tank using different two type controllers PID and fuzzy.

From program simulation that built it was indicates that the fuzzy controller has more Advantages to the system than the PID controller.

From the comparison between the two controllers it's clear that the fuzzy controller is more enhanced than PID in which its show No overshoot, respectable robustness and low settling and rising time. Moreover, it has a strong capability to response to the changes of the system parameters and antidisturbance Performance.

The fuzzy controller gives better performance in terms of Error indices such as IAE, ISE, ITAE and ITSE, respectively.

The future scope of this work is using fuzzy controller in SCADA system in water distribution system as well as its real time implementation which include using Arduino microprocessor for data acquisitions and controlling the operation of variable speed pump, the level will collect through ultrasonic level sensor and Human Machine Interface (HMI) will built by using LabVIEW .

\section{REFERENCES}

[1] Bequette, B. W.2003, "Process Control Modelling, Design and Simulation",Prentice Hall.

[2] Sudheer, L. Shrimanth .2013, “ step variation studies of ARM7 microcontroller based Fuzzy logic controller for water-in-tank level control", (IJEET), Vol.4, pp. 405-415
[3] Smith, C. A and Corripio .2006, A. B, "Principles and Practice of Automatic Process Control", 3rd ed., John Wiley \& Sons, Inc.

[4] "Labview PID and Fuzzy Logic Toolkit User Manual by national instrument”, 2009.

[5] Zuo, X. 2010, "Liquid level control of water tank system based on improved polyclonal selection algorithm and RBF network", IEEE, 2nd International Conference on Computer Engineering and Technology, Vol 2, p 528532.

[6] Xiao, Q. 2010, "Fuzzy Adaptive PID Control Tank Level”, IEEE, International Conference on Multimedia Communications, p149-152.

[7] Eyabi, P. B.1999, "Real time fuzzy logic and PID implemetation and control in LabView" ,Master's Theses. Paper 1805, San Jose State University.

[8] Nnochiri , U. 2014, "Comparison Study between Fuzzy Logic Controller (FLC) and Proportional-IntegralDerivative (PID) in Controlling of Liquid Flow", International Journal of Engineering and Technical Research (IJETR), Vol-2.

[9] BinYusof, A.Muhyiddin.2013, "A comparative study of conventional PID and FUZZY-PID for DC motor speed control", Master's Theses, Universiti Tun Hussein Onn Malaysia.

[10] Kiam Heong Ang.2005, "PID Control System Analysis, Design, and Technology", IEEE, transactions on control systems technology, vol. 13, No. 4.

[11] Mahmood, A. Kidher.2013, "Design Fuzzy Logic Controller for Liquid Level Control", International Journal of Emerging Science and Engineering (IJESE), Vol-1, Issue-11.

[12] Mihaela, R. and Eugen, R. 2011, "Fuzzy controller for adjustment of liquid level in the tank", University of Craiova, Mathematics and Computer Science, Vol.38, P $33-43$

[13] Jian-jun, Zhu .2014, "Design of Fuzzy Control System for Tank Liquid Level Based on WinCC and Matlab", IEEE, 13th International Symposium on Distributed Computing and Applications to Business, Engineering and Science, p 55-57.

[14] Kavitha, S. 2012, "Fuzzy Based Control Using Lab view For Temperature Process", International Journal of Advanced Computer Research, Vol-2, No-4, Issue-6. 